\title{
Facing crisis periods: a proposal for an integrative model of environmental scanning and strategic issue diagnosis
}

\author{
Natalia García-Carbonell ${ }^{1}$ · Fernando Martín-Alcázar ${ }^{1}$. \\ Gonzalo Sánchez-Gardey ${ }^{1}$
}

Received: 5 February 2020 / Accepted: 11 December 2020 / Published online: 4 January 2021

(c) The Author(s), under exclusive licence to Springer-Verlag GmbH, DE part of Springer Nature 2021

\begin{abstract}
The aim of this study is to examine the way top managers scan environmental conditions to diagnose and interpret issues during periods of crisis. Despite each of these processes being widely and individually represented in the research literature, there is a lack of integrative models that examine their internal dynamics in-depth. In this study, structural equation modeling methodology (EQS 6.3) was applied to a sample of 120 top managers to examine how the cognitive orientation of scanning (rational vs. intuitive analysis of environment) may influence final issue categorizations. Results confirm that not only is procedural rationality needed when scanning the environment, as traditional arguments have posited, but also that intuition plays a relevant role, complementing rational processes and configuring a mixed set of competencies to assess different issue dimensions, such as favorability, urgency, and influence.
\end{abstract}

Keywords Environmental scanning $\cdot$ Strategic issue diagnosis $\cdot$ Multidimensional interpretation · Intuition · Procedural rationality

JEL Classification M10

Natalia García-Carbonell

natalia.carbonell@uca.es

Fernando Martín-Alcázar

fernando.martin@uca.es

Gonzalo Sánchez-Gardey

gonzalo.sanchez@uca.es

1 Faculty of Business and Management, University of Cádiz, Avenida Enrique Villegas Vélez, 2,

11002 Cádiz, Spain 


\section{Introduction}

Contexts such as the 2008 economic crisis and more recently the COVID-19 pandemic have dramatically changed conditions under which firms have competed. The current pandemic is contributing to a severe financial global crisis, the real economic effects of which remain unclear (Ehrig and Foss, in press). Accordingly, the World Trade Organization (WTO) has recently estimated that the gross domestic product (GDP) of most economies will decrease by approximately 2.4 to 3.0 percent during 2020 (Verma and Gustafsson 2020). To address such as disturbing issues, companies have been pushed to change their business strategies, looking for new and resilient work philosophies (Ivanov 2020). In this context, the organizational competencies of collecting, processing, and interpreting information from the external environment can be considered a source of competitive advantage (Miller and Lin 2015; Sund 2015), as they try to sense and shape potential opportunities and threats in order to survive (Teece 2007).

The literature has traditionally defined a systematic process of issue management composed of three core steps (Daft and Weick 1984), as follows: (1) the environmental scanning process by which firms identify the relevant information, (2) strategic issue interpretation, evaluating and giving a specific meaning to the collected data, and (3) strategic response, as the final stage, by which the firm formulates and implements strategic plans. The notion behind this process is that top managers have to deal with environmental developments that are still uncertain issues, and they have to ensure there is early identification to enable a quick response (Ansoff 1980; Laamanen et al. 2018).

Despite the scanning-interpretation process being widely recognized in the literature, results on this topic are very dispersed and fragmented. Therefore, more research is needed to advance understanding of those dynamics and factors that condition appropriate processes for the scanning and diagnosis of issues (Shepherd et al. 2017; Laamanen et al. 2018; Joseph and Gaba 2020). In particular, this paper addresses two main aspects from the literature (Table 1):

a) The need to propose integrative models of scanning-interpretation by highlighting the interdependence between the two, and the role of scanning processes and their function as the input for the interpretation phase (Joseph and Gaba 2020).

b) The lack of study on deepening the link between the scanning and interpretation stages from an alternative point of view by introducing managers' cognitive skills in scanning processes as determinants of final categorizations (Csaszar 2018).

Accordingly, this study utilizes issue management literature to examine how rational environmental scanning compares with intuitive environmental scanning in influencing subsequent issue diagnosis and interpretation. Although these phases are closely linked, they configure different realities in issue management processes, each affecting and conditioning the other (Heugens 2006). 
Table 1 Contributions and limitations on Strategic Issue Management

\begin{tabular}{ll}
\hline Main contributions of the extant literature & Limitations to be addressed in the study \\
\hline $\begin{array}{l}\text { Especial attention to environments is needed to } \\
\text { anticipate and deal with changes, creating strate- } \\
\text { gic responses }\end{array}$ & $\begin{array}{c}\text { Mostly admit the existence of both stages: scanning } \\
\text { and interpretation, however, the focus is usually } \\
\text { on the final categorizations, leading to certain } \\
\text { strategic responses }\end{array}$ \\
$\begin{array}{l}\text { Environmental scanning and issue interpretation as } \\
\text { main stages in the process }\end{array}$ & $\begin{array}{c}\text { Mostly assume the connection between both stages } \\
\text { but they do not put much emphasis on explaining } \\
\text { it explicitly }\end{array}$ \\
$\begin{array}{l}\text { Traditional categorizations: Opportunity/Threat } \\
\text { framework }\end{array}$ & $\begin{array}{c}\text { Mostly assume the importance of managers' cogni- } \\
\text { tive skills but they do not examine them explicitly }\end{array}$ \\
Update works extend the perspective of categoriza- \\
tion included the Feasibility/Urgency framework \\
$\begin{array}{l}\text { Integration of ways of categorizations: Favorabil- } \\
\text { ity-Influence-Urgency model (Julian and Ofori- }\end{array}$ \\
\begin{tabular}{l} 
Dankwa 2008) \\
\hline
\end{tabular}
\end{tabular}

Source: Own elaboration

With this analysis, we contribute to the literature in two ways: (1) by proposing an integrative model of scanning-issue diagnosis from a theoretical point of view, and (2) by providing empirical evidence on the way the two strategic phases are connected. In particular, our results confirm that both procedural rationality and intuition are needed when scanning and interpreting information from the environment, shaping a dual set of competencies to evaluate different issue dimensions, such as favorability, urgency, and influence.

The paper is structured into three sections. Section 1 presents the theoretical framework on issue management and the development of hypotheses. In Sect. 2, we present the empirical test of the causal model derived from the theoretical discussion, using structural equation modeling with EQS on a sample of 120 Spanish top managers. Section 3 presents the conclusions, limitations, and areas for future research.

\section{Theoretical framework and hypotheses development}

\subsection{Environmental scanning: a dual process approach}

Crisis periods can be defined as "a moment of decisive intervention and not merely a moment of fragmentation, dislocation or destruction" (Hay 1999:317). In that contexts, top managers need to be constantly alert to changes to adapt, maintain, or change their current strategy (Floyd and Lane 2000). In general, the literature has posited that the broader the information scanning activities, the greater the organizational performance. This has emphasized differences in the way companies look for strategic information (Babbar and Rai 1993; Ebrahimi 2000). More recently, Danneels (2008) explained that scanning is a strategic capability that enables the absorptive capacity of the firm to increase. 
The main objective of this process is to enable firms to forecast and identify the emergence of potential issues (Milliken 1990) by extracting the predominant traits of existing issues. Scanning is particularly relevant because it deals with vague and diffuse developments that have not yet achieved the status of a decision event (Dutton et al. 1983). This deliberative process entails different actions not only to obtain information on relevant events, but also to protect the company from uncertainty (Thompson 1967), to detect environmental changes (Sutcliffe 1994), and to align managers' perceptions with the real environment (Bourgeois 1985).

Although environmental scanning may be considered an easy task, the literature defines diverse ways of performing this strategic process. For example, Gollner (1983) distinguishes between two main actions: issue scanning and issue monitoring. The former refers to a proactive behavior by which organizations identify events that may affect current or futures strategies. The latter concerns updated information relating to a previously identified issue. Others, such as Hough and White (2004), refer to external and internal scanning, including the analysis of internal strengths and weaknesses of the company. Another proposal describes scanning as an active process, characterized as constant attention to the environment, rather than passive scanning, in which organizations maintain a state of alertness for non-routine and core information (Huber 1991).

In most cases, data collection activities precede issue interpretation (Daft and Weick, 1984), but do not necessarily result in organizational responses (Hough and White 2004:782). In fact, environmental scanning is often difficult to interpret; however, it provides the basis for better and deeper understanding of environments and guides strategic planning steps (Lester and Parnell 2008). In this vein, when scanning environments, managers should not only identify and relate different relevant factors, but also describe possible future developments to shape diverse potential scenarios (Ayres and Axtell 1996; Gausemeier et al. 1998; Jiang et al. 2017; Tiberius et al. 2020).

Because there are different ways to develop scanning activities, top managers' capabilities play a crucial role in this regard in the survival of their firms. On the one hand, the information-processing approach posits that more information usually helps managers to develop interpretations and label issues, which enables better performance (Kuvaas 2002). Thus, when managers face uncertain and complex environments, they usually expend more effort on collecting data and seeking new information to clarify the context in which they act (Dutton and Jackson 1987). On the other hand, in certain contexts, they reduce scanning activities and base their decisions on their own experience and knowledge. This focus implies a direct and linear relationship between environment complexity and data collection processes (Hough and White 2004). However, these arguments are limited in explaining the reality of scanning behaviors.

To address these concerns, literature on social cognitive processes offers an alternative explanation, proposing that managers who spend too much time on gathering information tend to implement fewer changes relating to issue interpretation (Kuvaas 2002). The logic behind this argument suggests that "there is a strong tendency for subsequent information gathering to be biased towards confirming its correctness, rather than finding contradictory evidence [...]" (Anderson and Nichols 
2007:369). Therefore, as the literature suggests, scanning usually decreases in situations where there are important levels of certainty or uncertainty (March and Simon 1958). This means that managers would prefer to make decisions based on their "gut feelings" and experiences. In uncertain contexts, it is possible that managers do not have access to information (May et al. 2000) or there may be too much information to be analyzed, resulting in managers having to cope with contradictory information (Hough and White 2004). Accordingly, Álvarez and Barney (2007) posit that creating opportunities is a better option to face uncertain contexts or sectors than discovering new businesses. In essence, "creating" implies that opportunities do not exist independent of entrepreneurs and they are not considered the result of market discontinuities and imperfections. In fact, information to foresee potential outcomes related to decision making may not yet exist in such a context.

In environments of high certainty, familiar situations can be addressed by applying managers' experience. Nevertheless, as Hough and White (2004) propose, top managers may extend greater effort to process information in a stable environment to seek new market or business opportunities, rather than to reduce information. Therefore, it can be argued that efficient scanning, which requires a versatile and flexible set of actions and abilities, needs to be developed. Hence, top managers need to be capable of adapting scanning efforts to different situations and objectives to shape a flexible information gathering process, which may then lead to different future scenarios (Gausemeier et al. 1998; Jiang et al. 2017). As Durance and Godet (2010:1488) explain "a scenario is not a future reality but rather a means to represent it with the aim of clarifying present action in light of possible and desirable futures".

On the base of this definition, the paper proposes that scanning effort, understood as a first step in the scenario management (Burmeister et al. 2004), should simultaneously involve two types of processes-intuitive and rational/comprehensive (Hodkingson and Clarke 2007; Calabretta et al. 2016) — in a dual process model of searching and reasoning (Basel and Brühl 2013). In the literature, it is also known as System 1 (intuitive) and System 2 (rational) (Kahneman and Klein 2009). The degree of deployed rationality has frequently been linked to strategic decisionmaking processes. A number of researchers have emphasized the effects of these processes on organizational performance and decision-making quality (Elbanna and Child 2007; Forbes 2007). Comprehensive analysis implies that managers emphasize search and research activities and factors in the environment, evaluating relevant information on the basis of certain criteria to identify and develop multiple alternative actions (Elbanna 2006) and future scenarios (Jing et al. 2017). Analytic processes are complex and slow, and also demand higher cognitive time and effort. Furthermore, their dynamics enable managers to reduce the complexity of strategic decisions, to minimize managers' cognitive biases, and even to increase agreement in the implementation of alternatives (Miller 2008).

Nevertheless, given the systematic approach and rigidity of such analytic processes, they are not always efficient (Dane and Patt 2007; Calabretta et al. 2016). This highlights the importance of intuitive processes as a complementary mode of reasoning (Sadler-Smith 2016). In essence, [...] "System 1 works in a domain-specific and contextualized manner using associative parallel processing" (Salas et al. 
2010:945). As with the comprehensive mode, an intuitive focus on the environment also implies problem definition, analysis, and integration, but from a less conscious perspective (Calabretta et al. 2016), solving problems spontaneously and unconsciously without being affected by intellect or alertness (Frederick 2005). It also includes both affective and cognitive elements (Chassy and Gobet, 2011) and allows a holistic association of elements (Dane and Patt 2007). Thus, the process should not be considered random or irrational. In fact, it is built upon experiences and a coherent understanding of issues and problems (Khatri and Ng 2000).

This paper adopts Kahneman and Klein's (2009) System 1 definition of “intuition as expertise" (Kahneman and Klein 2009; Salas et al. 2010). Intuition is understood as a way of thinking and therefore as cognition that appears when decision makers have reached a high level of knowledge in a certain field, derived from an extensive experience (Salas et al., 2010). Hence, as Akinci and Sadler-Smith (2012:116) posited, "informed intuition is the result of extensive and deliberate practice, reflection, feedback and analysis" (Dreyfus and Dreyfus 1986; Ericsson et al. 2007). Kahneman and Frederick (2002) explain that System 2 (rational) is implemented in a sequential, rule-based, and abstract way to solve problems spontaneously and unconsciously without being affected by intellect or alertness (Frederick 2005). Thus, some degree of intuition may be necessary in scanning environments to promote speed, agility, and the quality of decisions (Burke and Miller 1999). For instance, Grant (2003) argues that intuition will increase creativity and flexibility in the decision-making process, especially in dynamic environments. Moreover, Khatri and $\mathrm{Ng}$ (2000) found intuitive processes to be positively related to organizational performance in unstable environments and negatively related in stable environments.

Although further research is needed on how these two complementary processes work (Basel and Brühl 2013), some authors propose a dynamic connection between them (see Fig. 1). On the one hand, heuristics arise spontaneously from intuitive processes, providing input into rational processes to generate deliberative strategies. On the other hand, fallacies and biases may appear when rational processes fail to amend mistakes derived from intuitive processes (Kahneman and Frederick 2002).

Because decisions are neither based exclusively on rationality nor intuition, a combination of both strategies may be applied (Salas et al. 2010). In fact, different calls from the literature manifest a need for research on how these two processes

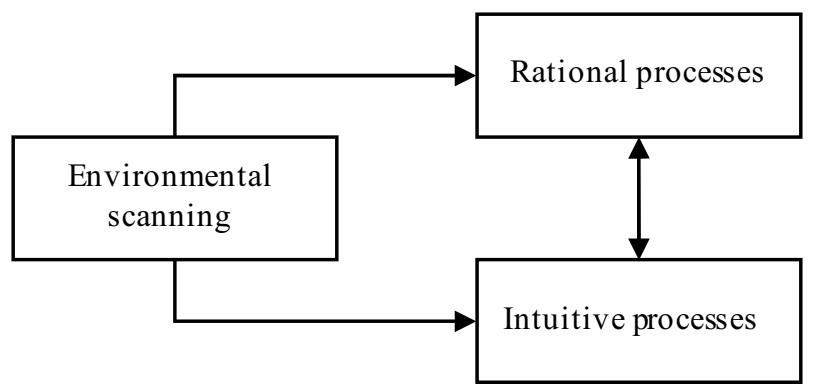

Fig. 1 A dual process model of environmental scanning 
work together (Gray 2004; Salas et al. 2010; Calabretta et al. 2016). Therefore, the logic behind these arguments is that, in a way, complementarities and synergies are possible from both rationality and intuition (Calabretta et al. 2016), helping top managers to scan and understand their environment. In the next section of the paper, we explain in more depth how certain cognitive orientation in environmental scanning may condition the subsequent interpretation of issues.

\subsection{Strategic issue interpretation: a multidimensional approach to interpretation}

Scanning activities are a necessity but not a sufficient condition for issue management and strategic responses (Hambrick 1982). The second stage of issue management refers to giving meaning to the data collected through scanning (Heugens 2006), and to translating external issues into shared meanings for the complete organization (Sund 2015). This part of the process is particularly relevant because it directly affects organizational responses and the scope of subsequent decision-making processes (Dutton et al. 1983).

The categorization and labelling of events requires important cognitive efforts and the application of mental maps (Dutton et al. 1983; Julian and Ofori-Dankwa 2008). In fact, a particular aspect detected in the environment can be considered a strategic issue for a company while irrelevant to others because "no issue is inherently strategic" (Dutton and Ashford 1993:397). Therefore, it can be argued that these two strategic phases are closely linked (Dutton et al. 1983; Sund 2015). This connection implies that environmental scanning provides the necessary input required to perform diagnosis of strategic issues. Depending on the external information provided, the results of such interpretation may vary. Therefore, we hypothesize the following:

- $\mathrm{H}_{1}$ : The greater the managers' effort to scan the environment, the greater the strategic issue interpretation process.

The most traditional model for the categorization of strategic issue diagnosis is the opportunity-threat framework (Jackson and Dutton 1988; Thomas et al. 1993). On the basis of two main dimensions-valence (positive-negative) and agency (controllable-uncontrollable)—-situations can be perceived as negative or problematic with the potential threat of loss or lack of organizational control. In such cases, these situations become labeled as "threats."

By contrast, opportunities present positive events that may lead to gains, and they are, to some extent, controllable (Thomas and McDaniel 1990). Usually, this type of categorization involves more automatic/affective interpretation processes, leading to "categorical and relatively unreflective interpretations" (Dutton 1997:87). In fact, such processes demand fewer cognitive resources and less effort, leading to interpretations based on "gut feelings" about the relative importance of the issue (Ginsberg and Venkatraman 1995).

As already mentioned, categorizations significantly condition strategic actions in diverse ways, deploying either proactive or reactive behaviors. Studies suggest that organizations usually increase control over their actions and reduce information 
flows and participation in decision making when responding to perceived threats (Staw et al. 1981). Researchers have posited that when interpreting opportunities, companies tend to be more proactive, seeking new products, innovation, or diversification (Schneider and De Meyer 1991). For example, Parida et al. (2016) posit that entrepreneurs who perceive the environment to be controllable increase the likelihood of initial sales from low-to-medium levels. More recently, Seetharaman (2020) defend that, in the context of COVID-19 pandemic, organizations find environmental variability to be a source of opportunities that can be turned into "temporary adhocracies" with the objective of innovating constantly to adapt their business models. As stated by Wenzel et al. (2020), innovating is one of the most predominant strategies to manage a period of crisis.

However, this method of categorization may entail an oversimplification of reality in some cases. Although correct simplification of the circumstances may help to stabilize the situation, in very specific and complex cases (such as the COVID-19 pandemic) oversimplification may produce inefficient decision-making processes (Ehrig and Jost, in press). To address this limitation, another stream of research proposed the feasibility-urgency framework (Dutton et al. 1990). Based on social construction theory (Daft and Weick 1984; Dutton et al. 1983), this more complex approach explains that organizations build their strategic responses by paying attention to two different criteria: (1) feasibility, understood as the organizational capacity to respond because of the importance of the strategic issue, and (2) urgency, which describes the time pressure and the visibility of the strategic issue (Dutton and Duncan 1987; Dutton et al. 1990). In practice, this approach requires more active/deliberative focus than the opportunity-threat model. Thus, interpretations require deeper and wider information searches and analyses (Dutton 1997; Julian and Ofori-Dankwa 2008), which lead to more conscious and intended processes.

Although strategic issue diagnosis models have been widely discussed in the literature, they lack descriptive accuracy. Consequently, they do not offer a detailed explanation of how managers interpret strategic issues in practice (Julian and OforiDankwa 2008). To address the limitations of previous models, an integrative model combining the two approaches described-the opportunity-threat and feasibilityurgency models-is proposed in the literature (Julian and Ofori-Dankwa 2008). In such an approach, the perceived relevance of the issue would be reflected through three dimensions. First, the "favorability" dimension indicates the degree to which the response to a strategic issue will result in a positive gain. Second, "urgency" relates to an assessment of the perceived importance in responding to a strategic issue. Third, "influence" refers to the perceived capacity of the organization to respond to a relevant event (Julian and Ofori-Dankwa 2008).

Empirical evidence shows that this integrative model explains the interpretation process better than previous models, confirming the empirical relevance of the three dimensions. The high complexity around strategic issues makes their interpretation especially difficult. Interpretations based only on a single dimension may lead to biased meanings and erroneous manager behavior (Julian and Ofori-Dankwa 2008: 110). In fact, the nature of issues, usually ill-defined and broad, may also produce ambivalent interpretations that simultaneously imply both positive and negative evaluations associated with an issue (Plambeck and Webber 2010; Yuan et al. 2017). 
Ambivalence, despite increasing the complexity of the interpretation processes, provides a more complete and accurate diagnosis of the issue, allowing the proposal of further actions (Jonas et al. 1997).

The generation of multiple futures based on interpretations of environmental factors is influenced by different aspects, such as managers' bounded rationality, cognitive biases, beliefs about the future, and communication processes implemented that also transmit scenarios (Tiberius 2019), leading to a particular set of biases that, as Schoemarker (1993) posited. To minimize biased and imprecise interpretations, the base on which managers shape future scenarios needs to be particularly clear for all participants, including labels, meanings, and their implications. Accordingly, we followed Julian and Ofori-Dankwa's (2008) arguments to explain issue interpretation as an integrated process through which favorability, urgency, and influence are jointly assessed. Thus, managers implement better diagnostic processes when they are able to detect the degree to which an issue may be favorable, urgent, or influential for the firm. This interpretation model provides a more complete and systematic framework with which to assess the strategic issues because of its greater applicability, which is more far-reaching than the traditional opportunity-threat and feasibility-urgency models (Fig. 2).

\subsection{An integrative model of interpretation}

Research on strategic issue management has traditionally focused on studying either the identification/scanning phase (Liao et al. 2008; Grégoire and Shepherd 2012; Shepherd et al. 2017), or the interpretation stage (Dutton et al. 1983; Julian and Ofori-Dankwa 2008; Miller and Lin 2015). However, the link between the two stages has been less frequently examined and tested (Shepherd et al. 2016).

As discussed, scanning and issue diagnosis are two of the most relevant managerial tools because they not only increase the chance of seizing opportunities, but also provide the means by which threats and potential problems may be faced. In practice, the complexity and importance of threats and problems mean that top managers constantly face the challenges of interpreting diverse environmental signals and

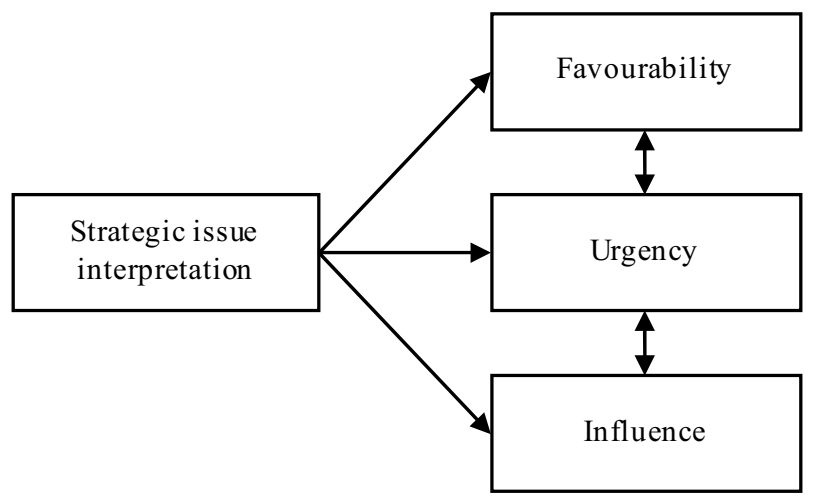

Fig. 2 A multidimensional process of issue diagnosis 
searching for the potential implications (and results) for their companies (Miller and Lin 2015).

With these two processes, the capacity of perception is crucial and logically it is different across managers. In fact, it is possible that managers suffer "inattentional blindness," which is "the failure to attend to an event that occurs during the performance of another task" (Helfat and Peteraf 2015: 839). In practice, managers do not pay exclusive attention to the environment, and even if they did, their focus may be biased in terms of how the issue is understood (Haas et al. 2015). Experts in certain areas may perceive information and issues more acutely and rapidly than those managers not considered to be experts. In such an intricate landscape, linking managers' cognitive skills - rational and intuitive - to issue interpretation helps us to put the two strategic phases together in an attempt to better understand how they function. Different issues require different levels of time, effort, number, and type of information sources to provide a clear idea of what they are about. Hence, the proposed model is based on the assumption that the way scanning is performed may influence perceptions across multiple dimensions in strategic diagnosis.

As previously mentioned, the literature has traditionally presented two competing frameworks to explain the effect of gathering information in the context of issue management. These are the information process approach, in which more information is understood to be positive because it usually implies a more complex understanding of the issue and provides support for initial interpretations, and the social cognitive process, in which further information is not always needed because there is a tendency to look for "biased" information that only confirms the preliminary interpretation rather than contradicting or reconsidering it (Anderson and Nichols 2007). In addition to these arguments, different works have considered that the interpretation of the issue (as either an opportunity or a threat) will affect subsequent actions, with opportunities demanding fewer actions than threats (Chattopadhyay et al. 2001; Anderson and Nichols 2007).

Considering these arguments and the dimensions included in the model, "favorability" was defined in terms of the potential positive gain a firm may obtain, similar to the concept of opportunity (Julian and Ofori-Dankwa 2008). If we apply the argument concerning the interpretation of automatic and analogical reasoning, top managers will detect and interpret environmental data based on their prior experiences, making inferences from past analogous situations (Miller and Lin 2015; Vecchiato 2020). This means more automatic/affective processes that require less cognitive effort would be implemented. In these situations, top managers would not need much information from the environment because they would perform 'relatively unreflective' interpretations based on previous experiences (Dutton 1997). Therefore, we may expect that managers will not need extra information because they do not aim to take action regarding the perceived opportunity, and accordingly they do not need to confront information to clarify or change their vision concerning the strategic issue in question.

Thus, the perception of issue favorability will be more precise when top managers implement intuitive processes during environmental scanning and subsequently interpret issues through automatic analogical reasoning. By contrast, cases of urgency and influence (because of their very nature and essence) are initially 
perceived to be negative and/or disturbing for the firm. In these cases, more information and data are needed to enable a clearer understanding of what is being analyzed, which may even change the managers' minds from their preliminary perception (Anderson and Nichols 2007). Based on these arguments, we propose the following sub-hypotheses (see Fig. 3).

- $\mathrm{H}_{2 \mathrm{a}}$ : Intuitive scanning processes lead to better interpretations of issue favorability than rational processes.

- $\mathrm{H}_{2 \mathrm{~b}}$ : Intuitive scanning processes lead to worse interpretations of issue urgency than rational processes.

- $\mathrm{H}_{2 \mathrm{c}}$ : Intuitive scanning processes lead to worse interpretations of issue influence than rational processes.

To complete the integrative model, we focus on the information-processing approach to explain that top managers need to scan the environment comprehensively to understand strategic issues (Hough and White 2004). This focus posits that exhaustive scanning processes will provide top managers with necessary and sufficient information to reduce any uncertainty around an event (Sund 2015). More information may help top managers to better understand and perceive the extent to which a certain event needs to be addressed within a short period; in short, to determine urgency.

Something similar happens with the "influence" dimension. Data and specific information about the way a certain issue should be addressed may facilitate top managers' perceptions about how an issue can be controlled by the firm. Comprehensive scanning processes imply a "much greater degree of information search and analysis" (Dutton 1997:87), and contrary to intuitive processes, may elicit more active and deliberative interpretations. Interpretations of the degree of urgency and the influence of an issue - both of which are intrinsically linked to threats (Julian

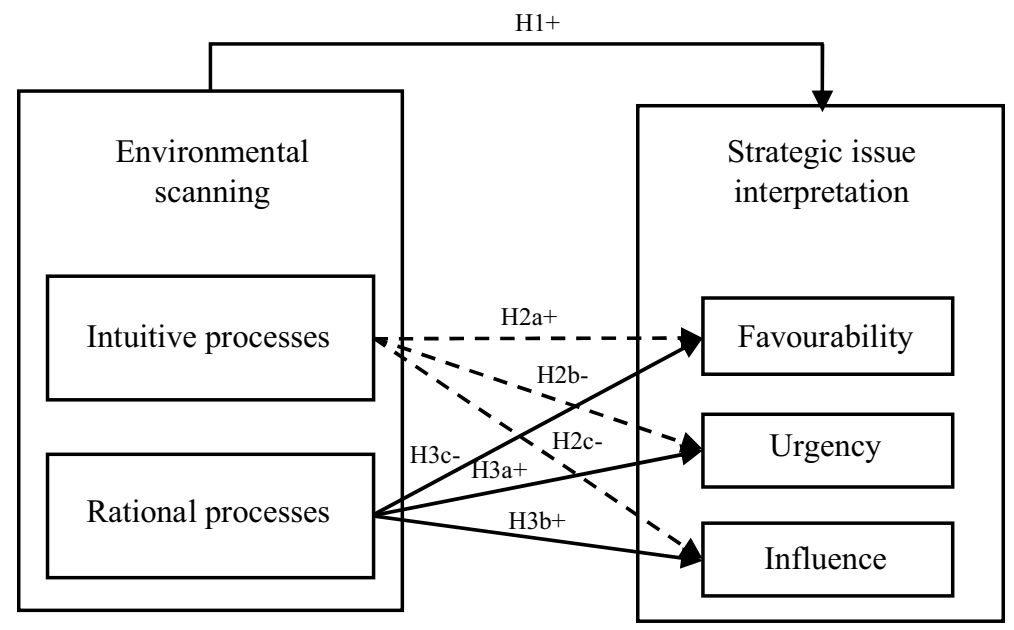

Fig. 3 Integrative model of interpretation: hypotheses 
and Ofori-Dankwa 2008)—will be more conscious and intentional. Therefore, as Gilbert (2006) posited, threats usually demand greater cognitive effort, being more cognitively taxing. Hence, we propose that top managers need to extract relevant information from the environment to offer objective and precise perceptions of the way an issue may influence a company and the level of urgency required in their response. Implicitly, and based on the arguments included in the previous hypothesis $\left(\mathrm{H}_{2 \mathrm{a}}\right)$, events that seem favorable for the firm tend not to require much information to be understood and interpreted. In general (although opportunities are of interest to companies), they neither imply a crucial concern for managers in terms of potential losses nor require quick and reactive actions to be managed (Anderson and Nichols 2007). Thus, to some extent, exhaustive analysis of environmental information could be ineffective. Therefore, we propose the following hypotheses (see Fig. 3).

- $\mathrm{H}_{3 \mathrm{a}}$ : Rational scanning processes lead to better perceptions of issue urgency than intuitive processes.

- $\mathrm{H}_{3 \mathrm{~b}}$ : Rational scanning processes lead to better perceptions of issue influence than intuitive processes.

- $\mathrm{H}_{3 \mathrm{c}}$ : Rational scanning processes lead to worse perceptions of issue favorability than intuitive processes.

\section{Empirical analysis}

\subsection{Sample, measures, and methods}

To explain the link between the scanning and interpretation stages by introducing managers' cognitive skills in scanning processes as determinants of final categorizations, data were collected using an online, self-administered questionnaire delivered to 290 Spanish top executives. To identify and contact potential respondents, we used the membership database of the Spanish Association for People Management and Development (AEDIPE).

Strategic managers were considered more direct and important agents deeply involved in strategic processes, such as environmental scanning and issue diagnosis (Hambrick 2007; Carmeli et al. 2009; Miller and Lin 2018). This is because their personal characteristics (cognitive processes, beliefs, personality traits, and ethical norms) definitively condition a firm's success. Therefore, higher responsibility is devolved to top managers (Abatecola and Cristofaro 2018). Although other managers may participate in such strategic processes (Raes et al. 2011), not always attending to other managers' inferences about strategic issues may lead to better results (Miller and Lin 2018).

The model was tested using structural equation modeling (SEM), specifically the EQS program (6.3 version), applying ordinary least squares-elliptical distribution (Bentler 2006). We paid special attention to missing values, asymmetry, and kurtosis, confirming that our sample followed a non-normal distribution pattern, from both multivariate and univariate perspectives. 
To assess the variables involved in the proposed model of study (degree of procedural rationality/comprehensiveness, degree of intuitive analysis, and capacity to interpret strategic issues) 7-point Likert-type scales were used, with response options ranging from $1=$ strongly disagree to $7=$ strongly agree. The questionnaire was designed according to suggestions by Fowler (2002) and Johnson and Harris (2002) concerning how items and scales should be defined to maximize validity and reliability. A pretest was conducted using an initial sample of respondents who provided feedback about the comprehensibility of the questions and the problems experienced while responding. Incomplete questionnaires were excluded, leaving 120 satisfactory responses (one respondent per firm). The final sample comprised a majority of large firms (48.5\% of the sample) in the following proportion: $3.4 \%$ building sector, $8,6 \%$ trade sector, $25 \%$ industry sector, and $62.9 \%$ remaining services.

We used validated scales from the literature to measure involved constructs (Appendix), as follows:

1) Degree of procedural rationality/comprehensiveness in environmental scanning. This was measured using Dean and Sharfman's (1996) scale. The Cronbach's alpha coefficient suggested that the new variable is internally consistent and reliable $(\alpha=0.853)$.

2) Degree of intuitive analysis Khatri and Ng's (2000). scale was applied to measure the degree to which top managers monitor the environment based on their own experiences and "gut feelings." The Cronbach's alpha presented acceptable levels of internal consistency $(\alpha=0.711)$.

3) Capacity to interpret strategic issues. The last construct introduced in the model was measured using Julian and Ofori-Dankwa's (2008) model to assess the three main dimensions in strategic issue diagnosis: favorability, urgency, and influence. The Cronbach's alpha confirmed its internal consistency $(\alpha=0.909)$.

Before testing the model, we conducted preliminary analysis with Q-Q plots and histograms, as well as the Kolmorogov-Smirnov's test to confirm the nonnormality character of the dataset. In addition, we conducted specific analysis of variance (ANOVA) to control for sector and size differences. The results confirmed that mean differences were not statistically significant (see Table 2).

Table 2 ANOVA analysis

\begin{tabular}{lrrrrr}
\hline ANOVA & \multicolumn{3}{l}{} \\
\hline Factors/Variables & \multicolumn{2}{l}{ Sector } & & & \multicolumn{2}{l}{ Size } & \\
\cline { 2 - 3 } \cline { 5 - 6 } & $\mathrm{F}$ & Sig. & & $\mathrm{F}$ & Sig. \\
\hline rationality & .370 & .775 & .432 & .651 \\
intuition & 1.515 & .217 & & 2.079 & .131 \\
influence & .486 & .693 & .598 & .552 \\
urgency & 1.138 & .339 & 1.619 & .204 \\
favourability & .670 & .573 & .458 & .634 \\
\hline
\end{tabular}




\subsection{Common method bias}

The nature of our model and dataset made it necessary to control for common method bias (CMB) problems. Following Podsakoff et al. (2003) and Podsakoff et al. (2012) recommendations, we performed two different sets of analyses: (1) procedural remedies or ex-ante remedies, and (2) specific statistical method or ex-post actions. For the first approach, we paid particular attention to the design of the study and the survey, protecting respondent anonymity and reducing evaluation apprehension. In doing so, an introductory paragraph specifying the objective of the study and its academic purposes was included in the survey. In addition, we provided some reverse coded items in the questionnaire, looking for a certain balance between positive and negative items to reduce socially desirable, lenient, or acquiescent opinions (Podsakoff et al. 2003: 888). Moreover, we used validated scales from the literature as Tourangeau et al. (1989) recommend, to minimize vague concepts and complex wording.

Regarding the second issue, Harman's one-factor test was conducted. Several factors emerged from the analysis in which the variance for the first factor was $41.47 \%$. Although Harman's single factor test has been widely used, it has been also rigorously criticized because of its limitations in controlling CMB. Therefore, additional and more complex statistical analyses were conducted.

Accordingly, we applied the unmeasured latent method construct (ULMC) technique, which introduces a first-order method factor whereby the measures are single indicators. Results showed that the majority of the method factor loadings were not statistically significant (15/17). Moreover, the indicators' substantive variances were higher than their method variances, also suggesting a relatively low level of CMB (Vance et al. 2008).

In addition, we assessed discriminant validity by comparing variable correlations with the squared root of average variance extracted (AVE) values for each of the constructs and calculating heterotrait-monotrait (HTMT) ratio scores, confirming that each construct represents a singular dimension of the model. Correlations exceeded the commonly accepted cut-off value of 0.90 (Table 3), while for the HTMT ratio, only two of the obtained values exceed 0.95 (Table 3). As Pavlou et al. (2007) posited, this evidence also suggests that $\mathrm{CMB}$ does not significantly condition our analyses.

\section{Results and discussion}

As previously stated, data in this study did not follow either univariate or multivariate normality, which led us to avoid the application of maximum likelihood estimation methods (Bentler 2006). Mardia's coefficient (42.222) and the analysis of asymmetry and kurtosis suggested the need to use ordinary least squares methods in the specific case of elliptical distributions (Bentler 2006).

Convergent validity for each construct of the measurement model was confirmed, showing most significant loadings at $5 \%$, with values generally over 0.5 . In addition, standard errors showed acceptable levels. As Table 3 demonstrates, discriminant validity was also confirmed with each AVE measure exceeding the 0.50 level (Bagozzi et al. 1991) and levels above the squared correlations between constructs (Hulland, 1999). As stated, HTMT analyses were conducted to complete the 
Table 3: Constructs, squared correlations, AVE and composite reliability, HMTM results

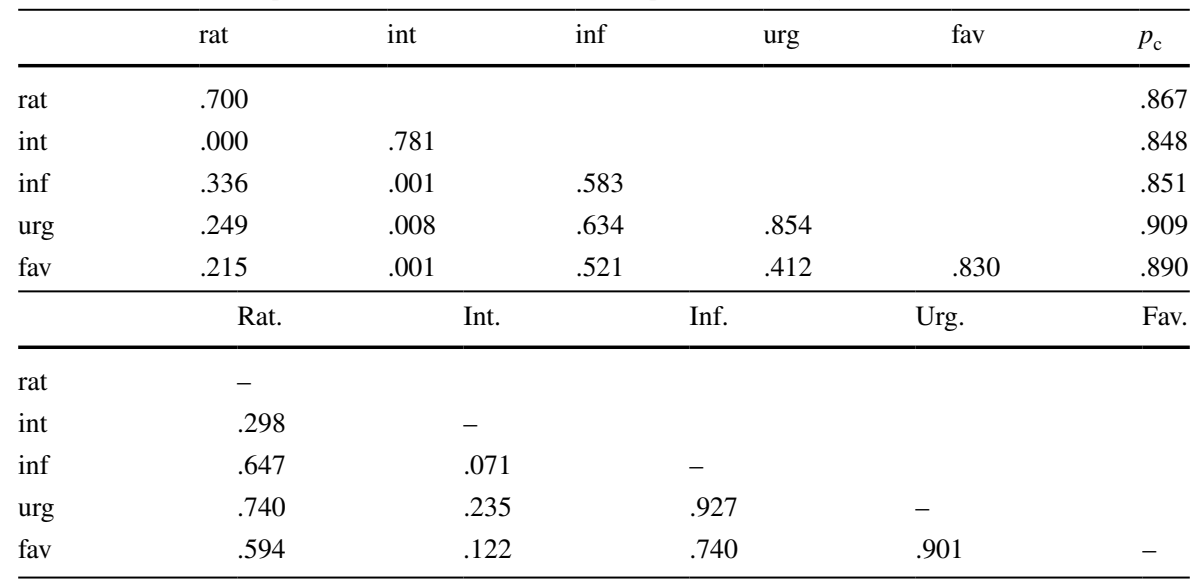

*AVE values appear in the diagonal for comparison with squared correlations under the diagonal to assess discriminant validity

previous analyses of discriminant validity (Table 3). More specifically, only two cases demonstrated levels over the liberal criterion HTMT $=0.90$ (Henseler et al. 2015). Finally, internal reliability was assessed through composite reliabilities, ranging from 0.848 to 0.909 (Nunnally and Bernstein 1994).

A set of equation analyses was conducted to examine the effects of comprehensiveness and intuition on different dimensions of strategic issue diagnosis in the structural model. The chi-square statistic is usually used to evaluate the fit of the model tested. In our case, the test provided a significant result at a 0.05 threshold $\left(\chi^{2}=189.561 ; N=120 ; \mathrm{df}=113 ;\right.$ sig. $\left.=0.00001\right)$. However, the chi-square is usually influenced by data non-normality, model complexity, and sample size, leading us to consider that there is a lack of fit between the sample and the covariance matrices (Byrne 1998). Different indices were therefore provided to address these problems and to obtain a broader and more precise view of the model fit (Kline 2005).

In fact, the rest of the indices obtained in our model showed an acceptable level of fit to the data. For absolute fit indices (to determine how well the a priori model fits the sample data) the results were as follows: GFI 0.97; AGFI 0.96; RMSEA 0.07; SRMR 0.08 . As observed, the indices ranged within appropriate levels, providing interesting evidence about how our date fits the theory. For incremental fit indices (comparing the fit of a substantive model to a null model) the results were as follows: NFI 0.91; NNFI 0.95; CFI 0.96 (Table 4). These levels were also acceptable, suggesting that the relationships included in the proposed model make sense and explain the reality.

These results partially support the proposed hypotheses and also offer additional interesting information. Regarding the first hypothesis, we found that having a greater ability to scan the environment improved the way top managers interpreted strategic issues. There was a positive and significant effect between different methods of scanning the environment and the dimensions included in the strategic issue interpretation. Specifically, $\mathrm{H}_{2 \mathrm{a}}$ was supported $(\beta=0.776$; $p<0.1$, indicating that intuitive processes help managers to better identify 
Table 4 Goodness fit indices

\begin{tabular}{lll}
\hline & Fit indices & Value \\
\hline Absolute fit indices & $\chi^{2}$ & $189.561 ;$ \\
& sig. $=0.00001$ \\
& $\chi^{2} / \mathrm{df}$ & 1.67 \\
& GFI & 0.97 \\
& AGFI & 0.96 \\
& RMR & 0.1 \\
& SRMR & 0.08 \\
& RMSEA & 0.07 \\
Incremental fit indices & NFI & 0.91 \\
& NNFI & 0.95 \\
& CFI & 0.96 \\
\hline
\end{tabular}

the degree of favorability of a certain issue. However, results indicated that exhaustive processes also improve favorability identification $\left(\mathrm{H}_{3 \mathrm{c}}\right)$, showing less intensity than intuition $(\beta=0.631 ; p<0.1)$. A similar result occurred for $\mathrm{H}_{3 \mathrm{a}}$ $(\beta=0.572 ; p<0.1)$ and $\mathrm{H}_{3 \mathrm{~b}}(\beta=0.506 ; \mathrm{p}<0.1)$. In these cases, the hypotheses were supported, suggesting that comprehensiveness is significant and positively linked to urgency and influence identification. Unexpectedly, we also found that intuition plays a positive role in detecting the dimensions of strategic issuesurgency $\left(\mathrm{H}_{2 \mathrm{~b}}: \beta=0.745 ; p<0.1\right)$ and influence $\left(\mathrm{H}_{2 \mathrm{c}}: \beta=0.673 ; \mathrm{p}<0.1\right)$-showing even higher intensity than comprehensive processes (Fig. 4).

These findings support the notion that a combination of the two strategies may lead to more complete and efficient strategic issue diagnosis processes (Hodgkinson and Clarke 2007; Calabretta et al. 2016). The synergies arising from the interaction of the two processes and their interdependence generate a complementary process of strategic issue diagnosis (Basel and Brühl 2013). In addition, the relative predominance of intuition in strategic issue diagnosis processes is especially interesting, considering the period when top managers were questioned. As mentioned, when the data collection process was conducted in 2013, Spain was still in economic crisis. Managers were asked about their decision-making processes, specifically the way that they scanned unstable environments and identified and interpreted crucial strategic issues to enable them to face the crisis. Different authors have already noted the relevance of intuition in decision-making during crisis (Sayegh et al. 2004; Calabretta et al. 2016; Li et al. 2016). However, some researchers dispute that intuitive decisions may be the most efficient form of decision making when facing time pressures and ambiguity in crisis situations (Lerner et al. 2015).

\section{Conclusions, limitations, and future research}

This paper explores the dynamics behind environmental issue management processes, detailing the way in which environmental scanning and strategic issue diagnosis are connected. Despite a number of researchers having examined these 


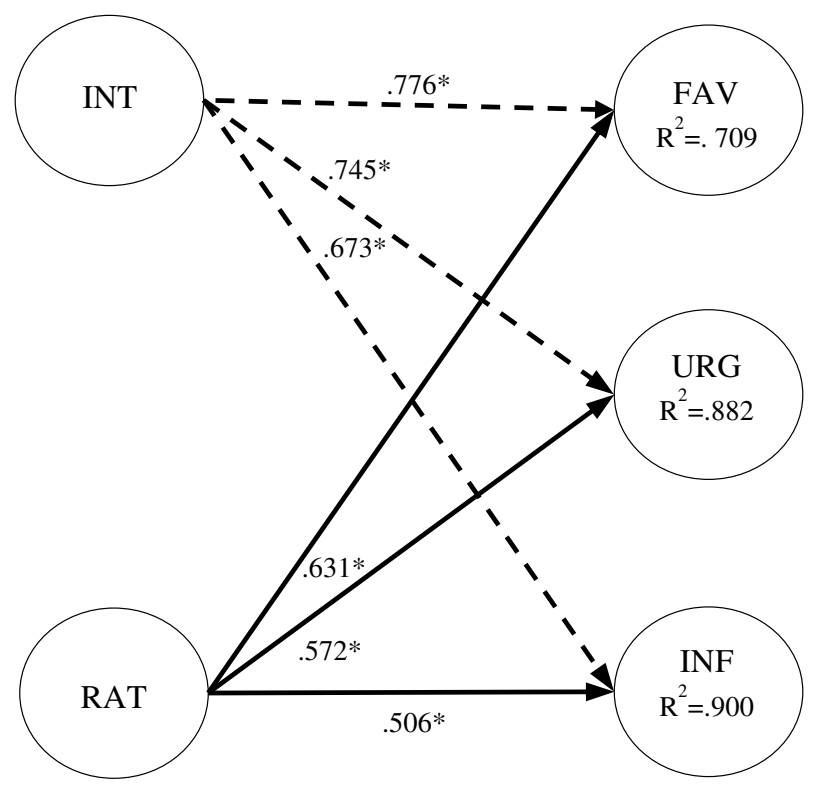

Fig. 4 Empirical analysis. Level of significance $\mathrm{p}<0.1$

processes in the literature on strategic contexts, there is a lack of studies analyzing both constructs simultaneously and the specific interactions between their dimensions (Shepherd et al. 2017).

One of the contributions of this research from a theoretical point of view is the proposal of an integrative model of interpretation in which both strategic stages are conceptually redefined from a multidimensional perspective. Traditionally, procedural rationality or comprehensiveness has been closely linked to efficient strategic decision-making processes (Cabantous and Gond 2011). However, processes of this kind should not be generalized to every situation, and can be combined with intuitive processes to generate internal synergies and gain efficiency (Calabretta et al. 2016). Environmental scanning is described in terms of the degree of rationality and intuition applied when managers examine the environment, assuming it as a dual process. This implies a broader process of scanning where more issues can be detected because of the synergies derived from the interplay between intuition and rationality (Calabretta et al. 2016). In this regard, Karhu and Ritala (2020:513) explain that "Managers should therefore pay close attention to situations that evoke mixed feelings; depending on the situation, they may decide to pursue their "gut feeling" where they are comfortable with the duality, or seek rational facts to back up decision-making in case of doubt."

Our model provides empirical confirmation of a relevant interaction between the two dimensions leading to different implications. On the one hand, procedural rationality contributes to the detection of crucial issues by gathering explicit and implicit information, applying explicit knowledge, calculating observations, and proposing alternative actions once managers implement logical information analysis 
(Ford and Gioia 2000). Because it is demanding of time and cognitive skills, the rational process is not always efficient by itself and needs to be complemented with intuitive orientation. Usually, in unstable environments, decisions should be made quickly to adapt to highly uncertain contexts, and the use of rational processes may hinder the decision-making process. In such environments, managers may also increase their efforts when looking for additional information to clarify the situation (Ehrig and Jost, in press). Therefore, ambivalence justifies the need to introduce intuition in the scanning process (Vecchiato 2020).

Conversely, intuitive processes should not always be understood as erratic or based on personal emotions (Khatri and Ng 2000). Although "imperfect intuition" exists (Kahneman and Klein 2009: 521) leading individuals to have "subjectively compelling intuitions," professional intuitions are built on tacit knowledge grounded in past experiences (Kleinmuntz 1990).

In this sense, intuition provides the scanning process with quick and coherent professional judgments, completing the rational analysis, which is especially interesting in the context of crisis. Consequently, our model describes and confirms the connection between intuition and rationality as the combination of the two dimensions where either one, depending on the situation (uncertainty, instability), can gain predominance. However, intuition usually provides the basis on which rationality is built (Sayegh et al. 2004). In practice, rational processes help to verify (with updated information) what managers already know from their experiences and tacit knowledge.

This internal functioning of environmental scanning also conditions the second stage of the process: strategic issue interpretation. We proposed an integrative model of issue interpretation following Julian and Ofori-Dankwa (2008). This allowed the model of interpretation to become more complete and precise, offering a broader perspective to categorize environmental issues. In contrast to our theoretical assumption, neither of the dimensions (intuition or rationality) was the best option alone for detecting urgency, favorability, or influence of an issue during periods of crisis.

As our empirical results show, both approaches to scanning the environment improved issue interpretation with a relative predominance of intuition. In other words, the combination of rationality and intuition appears to better explain the strategic issue dimensions, shaping relevant issues for the company (Hodgkinson and Clarke 2007; Calabretta et al. 2016).

In addition, the predominance of intuition may be explained in this case by considering specifically that managers responded during a period of crisis. In this vein, some authors have defended the importance of tacit knowledge and experiences in crisis decision making (Sayegh et al. 2004; Elbanna et al. 2013; Lerner et al. 2015; Li et al. 2016). Specifically, this tacit knowledge can be used through intuitive thought processes, providing speed, agility, and efficiency when interpreting issues. In other words, the use of tacit knowledge to complete the available information will improve the accuracy of perceptions and interpretations in crisis contexts (Brockman and Anthony 1998). Thus, interpreting issues will depend not only on tacit knowledge, but also on explicit knowledge from rational processes. In a crisis, deep rational decision making may require too much time and too many resources. However, part of the rational process can be performed, and it can be complemented with knowledge based on professional experiences (Sayegh et al. 2004). 
Conclusions derived from the theoretical development and empirical analysis lead us to propose different managerial implications.

Because issue interpretation in reality implies a number of complexities, such as different opinions between top managers, lack of clarity on what is interpreted, and turbulent and dynamic conditions, the first step before starting issue identification is that managers must have a clear idea of what they are assessing when addressing an issue. In periods of crisis, this becomes even more important because of environmental instability and complexity.

Therefore, based on the theoretical development of the paper, managers should extract relevant tools, such as Julian and Ofori-Dankwa's model, to ensure the application of complete and holistic models in practice. This model offers a clear framework to interpret strategic issues, considering three main dimensions, such as influence, favorability, and urgency. However, it is necessary that top managers work collectively on these definitions, agreeing their meanings in different contexts and sectors. Clarity of concepts in practice is extremely relevant to avoid ambiguity and vague categorizations. Thus, categorizations will be more precise, which is crucial for decision-making processes.

With regard to the empirical results, the influence and even the predominance of intuition over rationality shows that managers need to really understand the potential of intuition, and gain trust and knowledge about how and when it should be used (Elbanna et al. 2013). As part of their management education curriculum, they should receive training to implement better intuitive decisions, while the intrinsic preference for rational processes should be mitigated to allow better integration of rationality and intuition. Managers need an in-depth understanding of the contribution of each process and the ability to use them properly. Thus, organizations would foster the appearance of ambivalent cognitive skills at individual levels. In addition, from a group perspective, organizations may consider the need to integrate different and complementary cognitive profiles in their top teams, ensuring that not only individual managers but also top teams have the capability to implement complete strategic issue interpretation. Hence, recruitment and selection practices, as well as team building actions, should be oriented to this purpose.

As stated, the coexistence between rationality and intuition is not always easy. Usually, tensions arise between them demanding attention from managers. Specific practices for managing such tensions should be designed and implemented. For example, formal or informal meetings, presentations, simulations or workshops could foster openness and reduce resistance to this paradoxical thinking (Calabretta et al. 2016).

Such strategic processes (environmental scanning and issue interpretation) and the cognitive activity behind them, lead to different strategic responses to face dramatic crisis periods, such as the COVID-19 pandemic. In this respect, Kraus et al. (2013), in line to previous studies such as Kraus et al. (2013), recently posited that in most cases companies have adapted their strategies in a short period of time, using a combination of different strategies. In particular, Kraus et al. (2013) provided evidence confirming that companies tend to combine three types of strategies: innovation, retrenchment (reducing costs), and persevering (maintaining firms' operations). The results of this study show not only companies' capacity for resilience, but also the increasing complexity of strategies to be implemented coherently to the COVID-19 situation. One of the most recent strategies 
used in complex contexts is the "coopetition" strategy, because it contributes to different types of innovation due to the synergies derived from sharing resources, R\&D activities or access to knowledge (Roig-Tierno et al. 2018).

Some limitations should be considered when interpreting the results of the present research. First, we suggest the need to include an antecedent variable (decision motive), moderating variables (environment attributes such as complexity, uncertainty, and dynamism) or decision outcomes in future studies. The inclusion of such variables may enrich the conclusions of the research and provide a more detailed explanation of environmental issue management in current companies. In this vein, scenario management method may be a relevant framework to explain how managers deal with uncertainty in decision-making processes, shaping future success potentials (Tiberius et al. 2020). Furthermore, we find it particularly useful to focus on opportunities. These are the issues with the potential to impact companies positively, depending on how they are discovered or created, the nature of the opportunity, the nature of decision-makers, and the characteristic of the environment (degree of uncertainty). Second, the generalization of our results should be carefully limited for two reasons. First, all our data were obtained from large companies in the service sector, which implies a particular dynamic and approach to decision making. Second, potential cultural bias derived from the Spanish context may affect not only issue interpretation but also final decisions to be implemented. To address these limitations, future research could also focus on comparative analysis including international samples and consider the possible effects of different sectors. Finally, we find particularly interesting to deepen how these processes-environmental scanning and issue interpretation-are developed in dramatic situations, such as the COVID-19 pandemic, and how they may condition strategic responses.

We are also aware of the limitations of a single respondent questionnaire. Although we have considered study design recommendations for future research to avoid this problem, obtaining data from top management teams would also help mitigate possible response bias. In addition, the use of longitudinal data would help to reduce the problems associated with having single respondents and would enrich knowledge about the complete environmental issue management process. Furthermore, we would minimize the limitations from single respondents by obtaining responses from other managers and configuring a multiple-agent model (Miller and Lin 2018).

Acknowledgements The authors appear in alphabetical order and have contributed equally to this paper. The research project described in this paper was developed under the Research Group SEJ-449 funded by the Andalusian Government (Andalusian Plan for R\&D\&I 2007-2013) and the Research Projects ECO2014-56580-R funded by the Spanish Ministry for Science and Technology (Non-oriented Fundamental Research Projects Subprogram) and P12-SEJ-1810 (Andalusian Government).

\section{Appendix}

See Table 5 


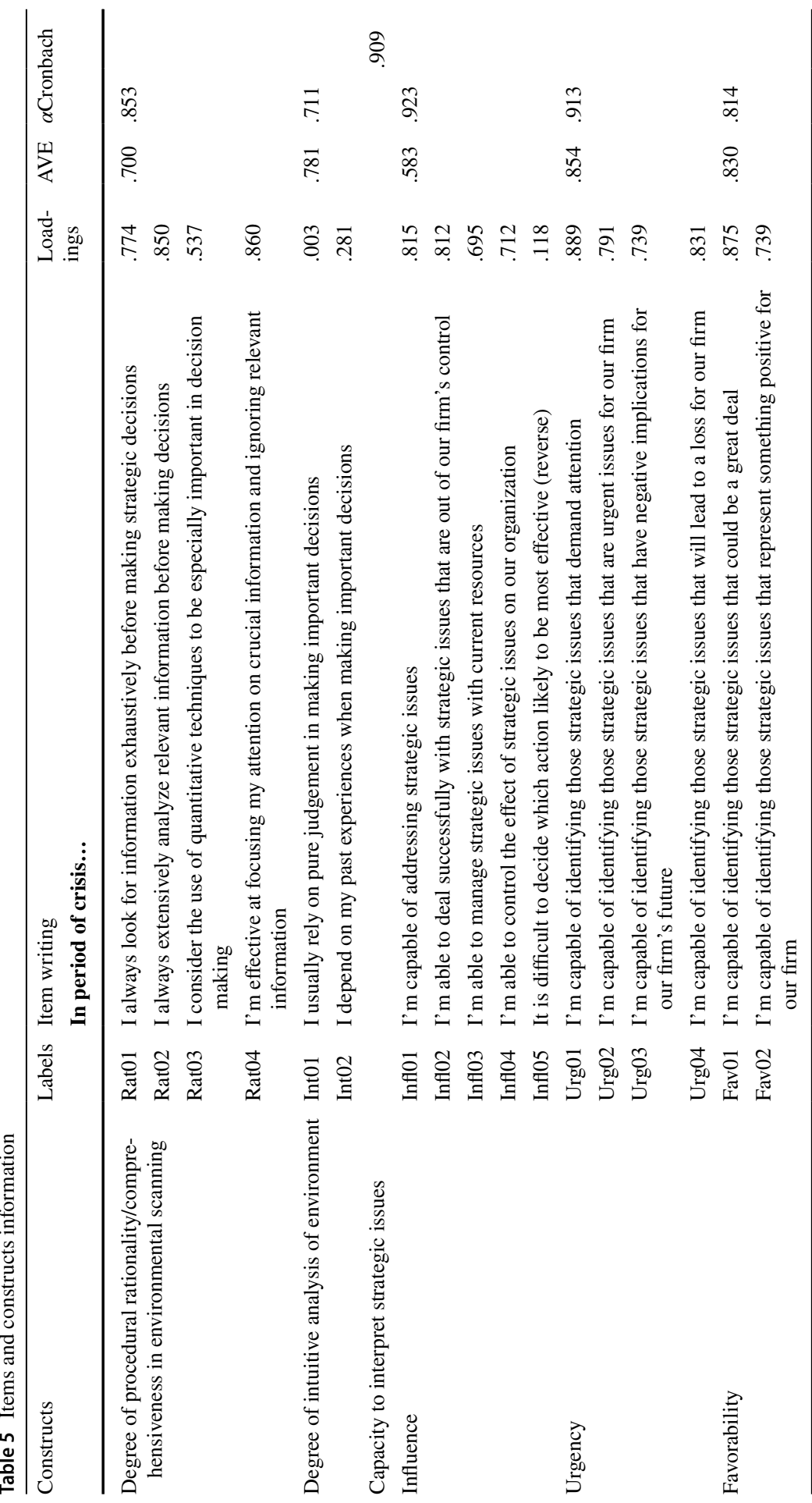




\section{References}

Abatecola G, Cristofaro M (2018) Hambrick and Mason's "Upper Echelons Theory": evolution and open avenues. J Manag Hist 26(1):116-136. https://doi.org/10.1108/JMH-02-2018-0016

Akinci C, Sadler-Smith E (2012) Intuition in management research: a historical review. Int J Manag Rev 14(1):104-122. https://doi.org/10.1111/j.1468-2370.2011.00313.x

Alvarez SA, Barney JB (2007) Discovery and creation: alternative theories of entrepreneurial action. Strat Entrep J 1(1-2):11-26. https://doi.org/10.1002/sej.4

Anderson MH, Nichols ML (2007) Information gathering and changes in threat and opportunity perceptions. J Manag Stud 44(3):367-387.

Ansoff HI (1980) Strategic issue management Strat Manag J 1:31-148. https://doi.org/10.1002/smj.42500 10204

Ayres RU, Axtell R (1996) Foresight as a survival characteristic: when (if ever) does the long view pay? Technol Forecast Soc Chang 51(3):209-235. https://doi.org/10.1016/0040-1625(95)00212-X

Babbar S, Rai A (1993) Competitive intelligence for international business. Long Range Plan 26(3):103113. https://doi.org/10.1016/0024-6301(93)90012-5

Bagozzi RP, Yi Y, Phillips LW (1991) Assessing construct validity in organizational research. Adm Scie Q 36(3):421-458. https://doi.org/10.2307/2393203

Basel JS, Brühl R (2013) Rationality and dual process models of reasoning in managerial cognition and decision making. Eur Manag J 31(6):745-754. https://doi.org/10.1016/j.emj.2013.07.004

Bentler PM (2006) EQS 6 structural equations program manual. Inc, Multivariate, Software Encino, CA

Bourgeois LJ (1985) Strategic goals, perceived uncertainty, and economic-performance in volatile environments. Acad Manag J 28(3):548-573. https://doi.org/10.2307/256113

Brockmann EN, Anthony WP (1998) The influence of tacit knowledge and collective mind on strategic planning. J Manag Issue 10(2):204-222.

Burke LA, Miller MK (1999) Taking the mystery out of intuitive decision-making. Acad Manag Executive 13(4):91-99. https://doi.org/10.5465/AME.1999.2570557

Burmeister K, Neef A, Beyers B (2004) Corporate foresight. Murmann Verlag, DE

Byrne BM (1998) Structural equation modeling with LISREL, PRELIS and SIMPLIS: basic concepts, applications and programming. Lawrence Erlbaum Associates, Mahwah New Jersey

Cabantous L, Gond JP (2011) Rational decision making as performative praxis: explaining rationality's eternal retour. Org Sci 22(3):573-586. https://doi.org/10.1287/orsc.1100.0534

Calabretta G, Gemser G, Wijnberg NM (2016) The interplay between intuition and rationality in strategic decision making: a paradox perspective. Organ Stud 38(3-4):365-401

Carmeli A, Sheaffer Z, Yitzack-Haveli M (2009) Does participatory decision-making in top management team enhance decision effectiveness and firm performance? Per Rev 38(6):696-714

Chassy P, Gobet F (2011) A hypothesis about the biological basis of expert intuition. Rev Gen Psychol 15(3):198-212. https://doi.org/10.1037/a0023958

Chattopadhyay P, Glick WH, Huber GP (2001) Organizational actions in response to threats and opportunities. Acad Manag J 44(5):937-955. https://doi.org/10.5465/3069439

Csaszar FA (2018) What makes a decision strategic? strategic representations. Strat Sci 3(4):606-619. https://doi.org/10.1287/stsc.2018.0067

Daft RL, Weick KE (1984) Toward a model of organizations as interpretation systems. Acad Manag Rev 9(2):284-295

Dane E, Pratt MG (2007) Exploring intuition and its role in managerial decision making. Acad Manag Rev 32(1):33-54. https://doi.org/10.5465/AMR.2007.23463682

Danneels E (2008) Organizational antecedents of second-order competences. Strat Manag J 29(5):519-543. https://doi.org/10.1002/smj.684

Dean JW, Sharfman MP (1996) Does decision process matter? a study of strategic decision-making effectiveness. Acad Manag J 39(2):368-392. https://doi.org/10.2307/256784

Dreyfus HL, Dreyfus SE (1986) The power of human intuition and expertise in the era of the computer. Mind over machine. The Free Press, New York

Durance P, Godet M (2010) Scenario building: uses and abuses. Technol Forecast Soc Chang 77(9):1488-1492. https://doi.org/10.1016/j.techfore.2010.06.007

Dutton A, Ashford SJ (1993) Selling issues to top management. Acad Manag Rev 18(3):397-428. https://doi.org/10.5465/AMR.1993.9309035145

Dutton JE (1997) Strategic agenda building in organizations. Org Dec Mak 81:105 
Dutton JE, Duncan RB (1987) The creation of momentum for change through the process of strategic issue diagnosis. Strat Manag J 8(3):279-295. https://doi.org/10.1002/smj.4250080306

Dutton JE, Fahey L, Narayanan VK (1983) Toward understanding strategic issue diagnosis. Strat Manag J 4(4):307-323. https://doi.org/10.1002/smj.4250040403

Dutton JE, Jackson SE (1987) Categorizing strategic issues: links to organizational action. Acad Manag Rev 12:76-90. https://doi.org/10.5465/AMR.1987.4306483

Dutton JE, Stumpf SA, Wagner D (1990) Diagnosing strategic issues and managerial investment of resources. Adv Strat Manag 6:143-167

Ebrahimi BP (2000) Perceived strategic uncertainty and environmental scanning behavior of Hong Kong Chinese executives. J Bus Res 49(1):67-77. https://doi.org/10.1016/S0148 $-2963(98) 00120-9$

Ehrig T, Jost, J. (in press) Boundedly rational strategic interaction and the interplay between complexity and simplification: Implications for strategy science. Strat Scie

Elbanna S (2006) Strategic decision-making: Process perspectives. Int J Manag Rev 8(1):1-20. https ://doi.org/10.1111/j.1468-2370.2006.00118.x

Elbanna S, Child J (2007) Influences on strategic decision effectiveness: development and test of an integrative model. Strat Manag J 28:431-453. https://doi.org/10.1002/smj.597

Elbanna S, Child J, Dayan M (2013) A model of antecedents and consequences of intuition in strategic decision-making: evidence from Egypt. Long Range Plan 46(1):149-176. https://doi. org/10.1016/j.lrp.2012.09.007

Ericsson KA, Prietula MJ, Cokely ET (2007) The making of an expert. Har Bus Rev 85:115-121

Floyd SW, Lane PJ (2000) Strategizing throughout the organization: managing role conflict in strategic renewal. Acad Manag Rev 25(1):154-177

Forbes DP (2007) Reconsidering the strategic implications of decision comprehensiveness. Acad Manag Rev 32(2):361-376. https://doi.org/10.5465/AMR.2007.24349585

Ford CM, Gioia DA (2000) Factors influencing creativity in the domain of managerial decision making. J Manag 26(4):705-732. https://doi.org/10.1177/014920630002600406

Fowler FJJr, (2002) Survey research methods. Sage Publications, Thousand Oaks, California

Frederick S (2005) Cognitive reflection and decision making. J Econ Perspect 19(4):25-42. https:// doi.org/10.1257/089533005775196732

Gausemeier J, Fink A, Schlake O (1998) Scenario management: an approach to develop future potentials. Technol Forecast Soc Chang 59(2):111-130. https://doi.org/10.1016/S0040 $-1625(97) 00166-2$

Gilbert CG (2006) Change in the presence of residual fit: can competing frames coexist? Org Sci 17(1):150-167. https://doi.org/10.1287/orsc. 1050.0160

Ginsberg A, Venkatraman N (1992) Investing in new information technology: the role of competitive posture and issue diagnosis. Strat Manag J 13:7-53. https://doi.org/10.1002/smj.4250131005

Gollner AB (1983) Social change and corporate strategy: the expanding role of public affairs. Issue Action, Stamford, CT

Grant RM (2003) Strategic planning in a turbulent environment: evidence from the oil majors. Strat Manag J 24(6):491-517. https://doi.org/10.1002/smj.314

Gray JR (2004) Integration of emotion and cognitive control. Curr Direct Psychol Sci 13(2):46-48. https ://doi.org/10.1111/j.0963-7214.2004.00272.x

Grégoire DA, Shepherd DA (2012) Technology-market combinations and the identification of entrepreneurial opportunities: an investigation of the opportunity-individual nexus. Acad Manag J 55(4):753-785. https://doi.org/10.5465/amj.2011.0126

Haas MR, Criscuolo P, George G (2015) Which problems to solve? online knowledge sharing and attention allocation in organizations. Acad Manag J 58(3):680-711. https://doi.org/10.5465/ amj.2013.0263

Hambrick DC (1982) Environmental scanning and organizational strategy. Strat Manag J 3(2):159-174. https://doi.org/10.1002/smj.4250030207

Hambrick DC (2007) Upper echelons theory: an update. Acad Manag Rev 32(2):334-343. https://doi. org/10.5465/amr.2007.24345254

Hay C (1999) Crisis and the structural transformation of the state: interrogating the process of change. $\mathrm{Br}$ J Pol Int Relat 1(3):317-344

Helfat CE, Peteraf MA (2015) Managerial cognitive capabilities and the microfoundations of dynamic capabilities. Strat Manag J 36(6):831-850. https://doi.org/10.1002/smj.2247 
Henseler J, Ringle CM, Sarstedt M (2015) A new criterion for assessing discriminant validity in variance-based structural equation modeling. J Acad Mark Scie 43(1):115-135

Heugens PP (2006) Environmental issue management: towards a multi-level theory of environmental management competence. Bus Strat Environ 15(6):363-376. https://doi.org/10.1002/bse.438

Hodgkinson GP, Clarke I (2007) Conceptual note: Exploring the cognitive significance of organizational strategizing: a dual-process framework and research agenda”. Hum Relat 60(1):243-255. https:// doi.org/10.1177/0018726707075297

Hough JR, White MA (2004) Environmental dynamism and strategic decision-making rationality: an examination at the decision level. Strat Manag J 24(5):481-489. https://doi.org/10.1002/smj.303

Huber GP (1991) Organizational learning: the contributing processes and the literatures. Org Sci 2(1):88115. https://doi.org/10.1287/orsc. 2.1 .88

Hulland J (1999) Use of partial least squares (PLS) in strategic management research: a review of four recent studies. Strat Manag J 20(2):195-204

Ivanov D (2020) Predicting the impacts of epidemic outbreaks on global supply chains: a simulationbased analysis on the coronavirus outbreak (COVID-19/SARS-CoV-2) case. Transp Res Part E: Logist Transp Rev 136:101922

Jackson SE, Dutton JE (1988) Discerning threats and opportunities. Adm Scie Q 33(3):370-387. https:// doi.org/10.2307/2392714

Jiang R, Kleer R, Piller FT (2017) Predicting the future of additive manufacturing: a Delphi study on economic and societal implications of 3D printing for 2030. Technol Forecast Soc Chang 117:84-97. https://doi.org/10.1016/j.techfore.2017.01.006

Johnson P, Harris D (2002) Qualitative and quantitative issues in research resign. In: Partington D (ed) Essential skills for management research. Sage Publications, London, pp 99-116

Jonas K, Diehl M, Brömer P (1997) Effects of attitudinal ambivalence on information processing and attitude-intention consistency. J Exp Soc Psychol 33(2):190-210

Joseph J, Gaba V (2020) Organizational structure, information processing, and decision-making: a retrospective and road map for research. Acad Manag Ann 14(1):267-302. https://doi.org/10.5465/ annals.2017.0103

Julian SD, Ofori-Dankwa JC (2008) Toward an integrative cartography of two strategic issue diagnosis frameworks. Strat Manag J 29(1):93-114. https://doi.org/10.1002/smj.647

Kahneman D, Frederick S (2002) Representativeness revisited: attribute substitution in intuitive judgment. In: Gilovich T, Griffin D, Kahneman D (eds) Heuristics and biases: the psychology of intuitive judgment. Cambridge University Press, Cambridge

Kahneman D, Klein G (2009) Conditions for intuitive expertise: a failure to disagree. Am Psychol 64(6):515

Karhu P, Ritala P (2020) The multiple faces of tension: dualities in decision-making. Rev Manag Scie 14(3):485-518. https://doi.org/10.1007/s11846-018-0298-8

Khatri N, Ng HA (2000) The role of intuition in strategic decision making. Hum Relat 53(1):57-86. https ://doi.org/10.1177/0018726700531004

Kleinmuntz B (1990) Why we still use our heads instead of formulas: Toward an integrative approach. Psychol Bull 107(3):296-310

Kline RB (2005) Principles and practices of structural equation modeling. Guilford Press, New York, NY

Kraus S, Moog P, Schlepphorst S, Raich M (2013) Crisis and turnaround management in SMEs: a qualitative-empirical investigation of 30 companies. Int J Entrep Venturing 5(4):406-430. https://doi. org/10.1504/IJEV.2013.058169

Kuvaas B (2002) An exploration of two competing perspectives on informational contexts in top management strategic issue interpretation. J Manag Stud 39(7):977-1001. https://doi. org/10.1111/1467-6486.00320

Laamanen T, Maula M, Kajanto M, Kunnas P (2018) The role of cognitive load in effective strategic issue management. Long Range Plan 51(4):625-639. https://doi.org/10.1016/j.lrp.2017.03.001

Lerner JS, Li Y, Valdesolo P, Kassam KS (2015) Emotion and decision-making. Annu Rev Psychol 66:799-823

Lester DL, Parnell JA (2008) Firm size and environmental scanning pursuits across organizational life cycle stages. J of Small Bus Enterp Dev 15(3):540-554. https://doi.org/10.1108/146260008108923 37

Li H, Huang L, Zhang Y, Ni S (2016) Effects of intuition and deliberation on escape judgment and decision-making under different complexities of crisis situations. Saf Sci 89:106-113. https://doi. org/10.1016/j.ssci.2016.06.006 
Liao J, Welsch H, Stoica M (2008) Environmental turbulence and scanning behavior: the moderating effects of organizational maturity. J Small Bus Strat 19(1):15-31

March JG, Simon HA (1958) Organizations. Wiley, NY

May RC, Stewart WH, Sweo R (2000) Environmental scanning behavior in a transitional economy: evidence from Russia. Acad Manag J 43(3):403-429. https://doi.org/10.2307/1556402

Miller CC (2008) Decisional comprehensiveness and firm performance: towards a more complete understanding. J Behav Decis Mak 21:598-620. https://doi.org/10.1002/bdm.607

Miller K, Lin SJ (2018) Strategic issue diagnosis by top management teams: a multiple-agent model. Acad Manag Proc 2018(1):16004

Miller KD, Lin SJ (2015) Analogical reasoning for diagnosing strategic issues in dynamic and complex environments. Strat Manag J 36(13):2000-2020. https://doi.org/10.1002/smj.2335

Milliken FJ (1990) Perceiving and interpreting environmental-change - an examination of college administrators' interpretation of changing demographics. Acad Manag J 33(1):42-63. https://doi. org/10.2307/256351

Nunnally JC, Bernstein IH (1994) Psychometric theory. McGraw- Hill, New York, NY

Parida V, George NM, Lahti T, Wincent J (2016) Influence of subjective interpretation, causation, and effectuation on initial venture sale. J Bus Res 69(11):4815-4819. https://doi.org/10.1016/j.jbusr es.2016.04.036

Pavlou PA, Liang H, Xue Y (2007) Understanding and mitigating uncertainty in online exchange relationships: a principal-agent perspective. MIS Q. 31(1):105-136

Plambeck N, Weber K (2010) When the glass is half full and half empty: CEOs' ambivalent interpretations of strategic issues. Strat Manag J 31(7):689-710

Podsakoff PM, MacKenzie SB, Podsakoff NP (2012) Sources of method bias in social science research and recommendations on how to control it. Annu Rev Psychol 63(1):539-569. https://doi. org/10.1146/annurev-psych-120710-100452

Podsakoff PM, MacKenzie SB, Lee JY, Podsakoff NP (2003) Common method biases in behavioral research: a critical review of the literature and recommended remedies. J Appl Psychol 88(5):879_ 903. https://doi.org/10.1037/0021-9010.88.5.879

Raes AML, Heijltjes MG, Glunk U, Roe RA (2011) The interface of the top management team and middle managers: a process model. Acad Manag Rev 36(1):102-126. https://doi.org/10.5465/ amr.2009.0088

Roig-Tierno N, Kraus S, Cruz S (2018) The relation between coopetition and innovation/entrepreneurship. Rev Manag Sci 12: 379-383 (2018). https://doi-org.bibezproxy.uca.es/https://doi. org/10.1007/s11846-017-0266-8DOI: https://doi.org/10.1007/s11846-017-0266-8 (in press)

Sadler-Smith E (2016) What happens when you intuit?' understanding human resource practitioners' subjective experience of intuition through a novel linguistic method. Hum Relat 69(5):1069-1093

Salas E, Rosen MA, Diaz-Granados D (2010) Expertise-based intuition and decision making in organizations. J Manag 36(4):941-973. https://doi.org/10.1177/0149206309350084

Sayegh L, Anthony WP, Perrewé PL (2004) Managerial decision-making under crisis: the role of emotion in an intuitive decision process. Hum Resour Manag Rev 14(2):179-199. https://doi.org/10.1016/j. hrmr.2004.05.002

Schneider SC, De Meyer A (1991) Interpreting and responding to strategic issues: the impact of national culture. Strat Manag J 12(4):307-320. https://doi.org/10.1002/smj.4250120406

Schoemaker PJ (1993) Multiple scenario development:iIts conceptual and behavioral foundation. Strat Manag J 14(3):193-213

Seetharaman P (2020) Business models shifts: impact of Covid-19. Intern J Inf Manag 54:102173. https ://doi.org/10.1016/j.ijinfomgt.2020.102173Get

Shepherd DA, McMullen JS, Ocasio W (2017) Is that an opportunity? an attention model of top managers' opportunity beliefs for strategic action. Strat Manag J 38:626-644. https://doi.org/10.1002/ smj.2499

Staw BM, Sandelands LE, Dutton JE (1981) Threat rigidity effects in organizational behavior: a multilevel analysis. Adm Scie Q 26(4):501-524. https://doi.org/10.2307/2392337

Sund KJ (2015) Revisiting organizational interpretation and three types of uncertainty. Intern J Organ Anal 23(4):588-605. https://doi.org/10.1108/JJOA-06-2013-0686

Sutcliffe KM (1994) What executives notice - accurate perceptions in top management teams. Acad Manag J 37(5):1360-1378. https://doi.org/10.2307/256677

Teece DJ (2007) Explicating dynamic capabilities: the nature and microfoundations of (sustainable) enterprise performance. Strateg Manag J 28(13):1319-1350 
Thomas JB, Clark SM, Gioia DA (1993) Strategic sensemaking and organizational performance: linkages among scanning, interpretation, action and outcomes. Acad Manag J 36(2):239-270. https://doi. org/10.2307/256522

Thomas JB, McDaniel RR (1990) Interpreting strategic issues: effects of strategy and the information-processing structure of top management teams. Acad Manag J 33(2):286-306. https://doi. org/10.2307/256326

Thompson J (1967) Organizations in action. McGraw-Hill, New York, NY

Tiberius V (2019) Scenarios in the strategy process: a framework of affordances and constraints. Eur J Future Res 7(1):1-14. https://doi.org/10.1186/s40309-019-0160-5

Tiberius V, Siglow C, Sendra-García J (2020) Scenarios in business and management: the current stock and research opportunities. J Bus Res 121:235-242. https://doi.org/10.1016/j.jbusres.2020.08.037

Tourangeau R, Rasinski KA, Bradburn N, D’Andrade R (1989) Belief accessibility and context effects in attitude measurement. J Exp Soc Psychol 25(5):401-421. https://doi.org/10.1016/00221031(89)90030-9

Vance A, Elie-Dit-Cosaque C, Straub DW (2008) Examining trust in information technology artifacts: the effects of system quality and culture. J Manag Inf Syst 24(4):73-100. https://doi.org/10.2753/ MIS0742-1222240403

Vecchiato R (2020) Analogical reasoning, cognition, and the response to technological change: lessons from mobile communication. Res Policy 49(5):103958. https://doi.org/10.1016/j.respo 1.2020 .103958

Verma S, Gustafsson A (2020) Investigating the emerging COVID-19 research trends in the field of business and management: a bibliometric analysis approach. J Bus Res. https://doi.org/10.1016/j.jbusr es.2020.06.057

Wenzel M, Stanske S, Lieberman MB (2020) Strategic responses to crisis. Strat Manag J. https://doi. org/10.1002/smj.3161

Yuan W, Bao Y, Olson BJ (2017) CEOs' ambivalent interpretations, organizational market capabilities, and corporate entrepreneurship as responses to strategic issues. J World Bus 52(2):312-326. https ://doi.org/10.1016/j.jwb.2016.12.009

Publisher's Note Springer Nature remains neutral with regard to jurisdictional claims in published maps and institutional affiliations. 